\title{
INVESTIGATING AN OUTBREAK OF NON-SPECIFIC BUILDING-RELATED SYMPTOMS IN WORKERS OF A GENERAL HOSPITAL
}

\author{
INÉS GÓMEZ-ACEBO ${ }^{1,2,3}$, TRINIDAD DIERSSEN-SOTOS ${ }^{1,2,3}$, \\ ELENA PÉREZ-BELMONTE ${ }^{4}$, and JAVIER LLORCA ${ }^{1,2,3}$ \\ ${ }^{1}$ University of Cantabria, Santander, Spain \\ Faculty of Medicine \\ ${ }^{2}$ CIBER Epidemiología y Salud Pública (CIBERESP), Spain \\ ${ }^{3}$ Instituto de Formación e Investigación Marqués de Valdecilla (IFIMAV), Santander, Spain \\ ${ }^{4}$ Hospital Universitario Marqués de Valdecilla, Cantabria, Spain \\ Department of Pediatrics
}

\begin{abstract}
Objective: To obtain a case definition and to describe variables associated with a cluster of unspecific symptoms in healthcare workers $(\mathrm{HCW})$ in a hospital building. Materials and Methods: A cross-sectional study was performed. All people working at the Residencia Cantabria building (a 200-bed building belonging to University Hospital Marqués de Valdecilla) in June 2009 were invited to complete a self-administered questionnaire, including questions on demographic data, working place and shift, working conditions and current symptoms. A cluster analysis was developed to obtain the case definition. The strength of the association between the studied variables and accomplishing the case definition was measured using odds ratios (OR) with the $95 \%$ confidence interval (CI). Multiple logistic regression was used to obtain a predictive model; its general validity was estimated with Receiver Operating Curves (ROC) and their Area Under the Curve (AUC). Results: 357 completed questionnaires were obtained. The case was defined as having at least 5 symptoms out of the eleven included. Not being ascribed to a specific shift was the strongest protective variable related with "being a case" $(\mathrm{OR}=0.30$; $95 \% \mathrm{CI}: 0.17-0.54)$, whereas the personal antecedent of distal pain or inflammation in arms or legs was the main risk factor $(\mathrm{OR}=4.33,95 \% \mathrm{CI}$ : 2.75-6.82). A six-variable predictive model has AUC equaling to 0.7378. Conclusions: A disease associated with the indoor environment quality in a hospital was characterized. A multivariate score was drafted for identifying $\mathrm{HCW}$ with higher risk of developing the disease in order to apply administrative prevention measures.
\end{abstract}

Key words:

Sick building syndrome, Cluster analysis, Healthcare workers, Predictive model

\section{INTRODUCTION}

Workplace environment has been related with a number of diseases, including sick building syndrome (SBS) and multiple kinds of chemical sensitivity. Indoor air quality (IAQ) encompasses temperature, lighting, volatile organic compounds (VOC) pollution, particulate matter concentration, humidity, ventilation, or even the control the workers have on these factors (for instance, the possibility of opening the windows). Buildings with heating, ventilation, and air conditioning (HVAC) systems have been reported to be more frequently affected, probably because they have higher pollution levels and a lower air

Received: January 16, 2013. Accepted: July 23, 2013.

Corresponding author: I. Gómez-Acebo, Facultad de Medicina, Universidad de Cantabria, Avda. Herrera Oria s/n, 39011 Santander, Spain (e-mail: ines.gomez@unican.es). 
exchange rate [1,2]. Symptoms associated with the workplace environment are unspecific; including especially such mucous membrane symptoms as eye irritation, nasal irritation, nasal congestion, throat irritation and voice hoarseness, and some general symptoms like headache, skin eruptions, and fatigue.

The relationship between the perceived IAQ and those symptoms remains controversial; several studies [3] suggested a causal relationship, but a well conducted prospective study reported that unspecific symptoms can precede the worsening of the IAQ perception, suggesting an inverse causality (i.e. people suffering from SBS can be more prone to complain about bad indoor environment conditions) [4]. Moreover, a cross-sectional study reported higher concentrations of particulate matter and VOCs in non-sealed buildings, while unspecific symptoms were more prevalent in sealed buildings [5].

\section{Antecedents}

At least from the end of 2005 on, the Service for Occupational Risk Prevention at the University Hospital Marqués de Valdecilla (Santander, Spain) received complains on bad odor in the Residencia Cantabria building (one of the main buildings in the hospital). The odor was experienced on several floors and in a number of units located far away from one another. Workers reporting "bad odor" also reported suffering from eye or throat irritation, a burning sensation on the skin, tongue ulcerations, and other mucous or cutaneous symptoms.

The building was inspected, including the HVAC system and the sanitation system, and cleaning and desinsection procedures were performed. Air concentrations of VOCs and pesticides were determined, and microbiological environmental pollution was studied. Having found no pollutants in high or even moderate concentrations, a number of engineering measures were taken: ventilation in Operating theaters was completely changed, filters were installed in sanitation systems, and affected workers were shifted to other units. In spite of these and other measures, the number of affected workers raised until 2009; local journals reported on this issue, which produced public concern on the safety of working in or even being admitted into the affected building.

In the winter of 2009, the University Hospital Marqués de Valdecilla contacted the Department of Epidemiology and Public Health at the University of Cantabria in order to carry out an epidemiological study to characterize the disease and to identify workers at higher risk. This article reports a cross-sectional study aimed to obtain a case definition and to describe the person, place and time variables associated with the disease in the Residencia Cantabria.

\section{MATERIALS AND METHODS}

\section{Setting}

The University Hospital Marqués de Valdecilla is a 900-bed reference hospital located in Santander, in the north of Spain; its reference area comprises about 590000 inhabitants. It has two main buildings separated by 300 meters: the general residence, with about 700 beds, which is currently being reconstructed, and the Residencia Cantabria, a formerly independent 200-bed hospital. The study was performed in the Residencia Cantabria building, which is 40 years old and which currently houses obstetrics, gynecology, pediatrics and general surgery.

\section{Study design}

A cross-sectional study was performed. All people working in the Residencia Cantabria building in June 2009 were invited to complete a self-administered questionnaire including questions on demographic data (age, sex, years worked in the Residencia Cantabria, working category), working place and shift, working conditions (for instance: temperature, ventilation, air conditioning, lighting, etc.), personal and family antecedents of disease, and current symptoms. 


\section{Statistical Analysis}

Due to the above-described controversy, an a priori case definition was not adopted. Instead of that, a cluster analysis was performed: people were classified into one of two previously undefined groups, using their answers to eleven questions on the current symptoms (Table 1) as inputs. This classification was used in order to obtain a case definition. The cluster analysis was performed with the application of the kmeans procedure in Stata 10/SE [6]. This is an iterative procedure that partitions the sample into $\mathrm{k}$ groups $(\mathrm{k}=2$ in our case); the procedure begins with two initial group centers; the subjects are assigned to the group with the closest center; then the mean of the subjects assigned to each group is computed, and the process is repeated until all subjects remain in the same group from the previous iteration [6].

The association of the demographic variables, working place, working conditions, and personal and family antecedents with accomplishing the case definition was studied by estimating odds ratios (OR) and $95 \%$ confidence intervals (CI). Multiple logistic regression was used to obtain a predictive model. Finally, the model was simplified in order to have an easy-to-use tool for predicting cases; its validity parameters (sensitivity, specificity and the likelihood ratio) were estimated, and its general validity was compared with the original model (i.e. the one obtained by logistic regression) by estimating ROC curves and their Area Under the Curve (AUC). The significance level was set up at 0.05.

\section{RESULTS}

Out of 451 answered questionnaires, 191 (44\%) were completed by nurses, $33(7.6 \%)$ by midwives, 148 $(36.6 \%)$ by nurse assistants, $17(4 \%)$ by porters, 20 $(4.6 \%)$ by administrative workers, and $13(3 \%)$ by staff belonging to other categories; no questionnaire was answered by a physician. The mean age of the respondents was 47.6 years (standard deviation: 9.4, median: 50, interquartilic range: 41-55). They had been working in the Residencia Cantabria for 14.4 years on average (standard deviation: 13, median: 8, interquartilic range: $3-28)$.

Table 1. Symptoms included in the case definition

\begin{tabular}{|c|c|}
\hline Symptoms & Answers* \\
\hline $\begin{array}{l}\text { Do you have or did you have symptoms that appear during your work shift and disappear when you leave } \\
\text { the workplace? }\end{array}$ & yes/no \\
\hline Do you have health problems that increase in the workplace but disappear after a week out of the workplace? & yes/no \\
\hline Do you have itching or dryness in your eyes, mouth, tongue or throat? & yes/no \\
\hline Do you have constipation that has recently appeared or your previous constipation has worsened? & yes/no \\
\hline Do you have skin eruptions in your workplace? & yes/no \\
\hline Do you need to drink or to moisten your eyes or your skin? & yes/no \\
\hline Do you notice numbness in your mouth, tongue or throat? & yes/no \\
\hline Do you notice metallic taste or have you lost your taste or your sense of smell? & yes/no \\
\hline Do you feel more tired than expected for your daily activity? & yes/no \\
\hline Do you have headache that has appeared recently or your previous headache has worsened? & yes/no \\
\hline $\begin{array}{l}\text { In the last year, have you suffered two or more episodes of cold or upper respiratory tract infection (faringitis, } \\
\text { amigdalitis, otitis or sinusitis)? }\end{array}$ & yes/no \\
\hline
\end{tabular}

* A healthcare worker in the Residencia Cantabria was classified as a case if he/she answered "yes" to 5 or more symptoms. 


\section{Case definition}

357 questionnaires had all answers provided to the eleven questions on the current disease, and so they were included in the cluster analysis. 192 were classified as "cluster A" and 165 as "cluster B". Every single question in Table 1 was positively related with being included in cluster A (results not shown); therefore, people included in "cluster A" were considered as "ill" and people included in "cluster B" were considered as "non-ill". Moreover, a strong relationship was found between the number of positive answers to the questions contained in Table 1 and belonging to "cluster A": all people but one with five or more positive answers were classified into "cluster A", while all but 20 people with four or less positive answers were classified into "cluster B" (Table 2). Therefore, the case of Residencia Cantabria's Disease (RC's Disease) was defined as having at least 5 symptoms out of eleven included in Table 1 . All results from here on refer to this case definition. This definition misclassified only 20 patients from cluster A as non-ill and one patient from cluster B as ill. Table 2 shows that any alternative definition based on the number of symptoms would produce a higher number of misclassified patients.

Table 2. Relationship between the number of symptoms (see Table 1) and belonging to clusters A or B

\begin{tabular}{lcc}
\hline \multirow{2}{*}{ No. of symptoms } & \multicolumn{2}{c}{ Patients (n) } \\
\cline { 2 - 3 } & cluster A & cluster B \\
\hline 0 & 0 & 46 \\
1 & 0 & 38 \\
2 & 0 & 35 \\
3 & 0 & 30 \\
4 & 20 & 15 \\
5 & 39 & 1 \\
6 & 35 & 0 \\
7 & 36 & 0 \\
8 & 28 & 0 \\
9 & 20 & 0 \\
10 & 8 & 0 \\
11 & 6 & 0 \\
\hline
\end{tabular}

\section{Variables related to cases}

Each consecutive year of working at the Residencia Cantabria increased the risk of suffering from the RC's Disease by 2\% (OR = 1.02; 95\% CI: 1.00-1.03); midwives (OR $=0.48 ; 95 \% \mathrm{CI}: 0.21-1.11)$ and porters $(\mathrm{OR}=0.17 ; 95 \%$ CI: 0.04-0.80) had a lower risk than nurses (reference group), while administrative workers had a double risk $(\mathrm{OR}=2.42 ; 95 \%$ CI: 0.91-6.39) of developing it. It is noteworthy that healthcare workers not ascribed to a specific working shift had a lower risk of developing the RC's Disease $(\mathrm{OR}=0.30$; 95\% CI: 0.17-0.54), while people working during the morning shift had a higher risk (Table 3 ). There was no association either with specific floors nor with specific units (operating rooms, wards, radiology etc.) (results not shown).

Table 3. Personal and occupational variables related with the case definition

\begin{tabular}{lcc}
\hline \multicolumn{1}{c}{ Variable } & OR $(95 \%$ CI $)$ & $\mathrm{p}$ \\
\hline Gender & & \\
$\quad$ woman (ref.: man) & $1.93(0.78-4.77)$ & 0.150 \\
Age & & \\
$\quad$ each additional year & $1.02(0.99-1.04)$ & 0.150 \\
Years working at the & & \\
$\quad$ Residencia Cantabria & & \\
each additional year & $1.02(1.00-1.03)$ & 0.010 \\
Profession & & \\
nurse & $1.00($ reference $)$ & - \\
midwife & $0.48(0.21-1.11)$ & 0.080 \\
nurse assistant & $1.06(0.69-1.62)$ & 0.780 \\
porter & $0.17(0.04-0.80)$ & 0.010 \\
administrative & $2.42(0.91-6.39)$ & 0.070 \\
Working shift & & \\
8:00 a.m. $-3: 00$ p.m. & $1.00($ reference $)$ & - \\
3:00-10:00 p.m. & $0.69(0.23-2.03)$ & 0.490 \\
10:00 p.m. $-8: 00$ a.m. & $0.49(0.15-1.61)$ & 0.230 \\
changing shifts & $0.30(0.17-0.54)$ & $<0.001$ \\
\hline
\end{tabular}

OR - odds ratio; $\mathrm{CI}$ - confidence interval. 
Several previous conditions were positively related with the RC's Disease (Table 4), namely intolerance to food other than cow milk (OR $=2.44 ; 95 \%$ CI: 1.40-4.25), growth pain $(\mathrm{OR}=1.96,95 \% \mathrm{CI}: 1.17-3.31)$, hypercholesterolemia $(\mathrm{OR}=1.65,95 \% \mathrm{CI}: 1.07-2.55)$, unexplained episodes of fever (OR $=2.50,95 \%$ CI: $1.27-4.89)$, history of allergies, urticaria or angioedema $(\mathrm{OR}=2.19$, 95\% CI: 1.44-3.34), history of skin rash, dermatitis or eczema $(\mathrm{OR}=1.93,95 \%$ CI: $1.28-2.91)$, easily sunburned skin $(\mathrm{OR}=1.73,95 \% \mathrm{CI}$ : 1.13-2.63), oral ulcerations $(\mathrm{OR}=1.58,95 \% \mathrm{CI}: 1.06-2.36)$, usually cold hands and feet $(\mathrm{OR}=2.11,95 \% \mathrm{CI}$ : 1.34-3.34), alopecia $(\mathrm{OR}=1.87,95 \% \mathrm{CI}: 1.21-2.88)$, distal pain or inflammation in arms or legs (OR $=4.33,95 \% \mathrm{CI}: 2.75-6.82)$, edema in ankles (OR $=2.42,95 \% \mathrm{CI}: 1.56-3.77)$, livedo reticularis $(\mathrm{OR}=2.88,95 \% \mathrm{CI}: 1.16-7.16)$.

Table 4. Personal antecedents related with the case definition

\begin{tabular}{|c|c|c|}
\hline Variable & OR $(95 \% \mathrm{CI})$ & $\mathrm{p}$ \\
\hline Feeling sick after drinking cow milk & $1.57(0.81-3.05)$ & 0.180 \\
\hline Intolerance to other foods & $2.44(1.40-4.25)$ & $<0.001$ \\
\hline Taking oral contraceptives & $1.22(0.83-1.78)$ & 0.310 \\
\hline Growth pain & $1.96(1.17-3.31)$ & 0.010 \\
\hline Hypercholesterolemia & $1.65(1.07-2.55)$ & 0.020 \\
\hline Amygdalitis, otitis or faringitis frequently during childhood & $1.05(0.72-1.53)$ & 0.800 \\
\hline Amygdalectomy & $0.91(0.61-1.34)$ & 0.630 \\
\hline Unexplained episodes of fever & $2.50(1.27-4.89)$ & 0.010 \\
\hline Rheumatic fever, lupus or psoriasis & $1.09(0.53-2.22)$ & 0.810 \\
\hline Allergies, urticaria, angioedema & $2.19(1.44-3.34)$ & $<0.001$ \\
\hline Asthma & $1.85(0.73-4.71)$ & 0.190 \\
\hline Erithema, dermatitis, eccema & $1.93(1.28-2.91)$ & $<0.001$ \\
\hline Sunlight easily produces discomfort, fatigue, red stains or burns & $1.73(1.13-2.63)$ & 0.010 \\
\hline Skin or joint symptoms that passed after the use of steroids & $1.50(0.97-2.33)$ & 0.070 \\
\hline Pregnancies & $1.75(1.18-2.59)$ & 0.010 \\
\hline Abortions & $1.34(0.80-2.24)$ & 0.270 \\
\hline Preterm delivery or low-weighted newborn & $0.90(0.46-1.76)$ & 0.760 \\
\hline Thyroid disease & $1.57(0.89-2.78)$ & 0.120 \\
\hline Oral ulcerations & $1.58(1.06-2.36)$ & 0.020 \\
\hline Usually cold hands and feet, or color changes in fingers in cold temperature & $2.11(1.34-3.34)$ & $<0.001$ \\
\hline Alopecia & $1.87(1.21-2.88)$ & $<0.001$ \\
\hline Pain, inflammation, or rigidity in wrists, hands, ankles, feet or knees & $4.33(2.75-6.82)$ & $<0.001$ \\
\hline Episodes of unconsciousness & $1.89(0.92-3.89)$ & 0.080 \\
\hline Dyspnea, tightness in the chest during physical effort & $4.77(2.66-8.57)$ & $<0.001$ \\
\hline Edema in ankles & $2.42(1.56-3.77)$ & $<0.001$ \\
\hline Lack of memory or mental concentration & $4.31(2.74-6.77)$ & $<0.001$ \\
\hline Livedo reticularis & $2.88(1.16-7.16)$ & 0.020 \\
\hline
\end{tabular}

Abbreviations as in Table 3. 
Table 5. Perceived indoor environment quality at the workplace and the case definition

\begin{tabular}{|c|c|c|}
\hline Variable* & OR $(95 \% \mathrm{CI})$ & $\mathrm{p}$ \\
\hline \multicolumn{3}{|l|}{ Light } \\
\hline 1 (reference) & 1.00 & - \\
\hline 2 & $0.39(0.19-0.83)$ & 0.010 \\
\hline 3 & $0.52(0.28-0.96$ & 0.030 \\
\hline 4 & $0.23(0.11-0.49)$ & $<0.001$ \\
\hline 5 & $0.35(0.18-0.68)$ & $<0.001$ \\
\hline \multicolumn{3}{|l|}{ Ventilation } \\
\hline 1 (reference) & 1.00 & \\
\hline 2 & $0.43(0.24-0.76)$ & $<0.001$ \\
\hline 3 & $0.33(0.19-0.59)$ & $<0.001$ \\
\hline 4 & $0.27(0.13-0.54)$ & $<0.001$ \\
\hline 5 & $0.46(0.23-0.89)$ & 0.020 \\
\hline \multicolumn{3}{|l|}{ Temperature } \\
\hline 1 (reference) & 1.00 & \\
\hline 2 & $0.74(0.46-1.22)$ & 0.240 \\
\hline 3 & $0.52(0.31-0.89)$ & 0.010 \\
\hline 4 & $0.50(0.22-1.10)$ & 0.080 \\
\hline 5 & $0.62(0.25-1.57)$ & 0.310 \\
\hline \multicolumn{3}{|l|}{ Noise } \\
\hline 1 (reference) & 1.00 & \\
\hline 2 & $0.33(0.17-0.65)$ & $<0.001$ \\
\hline 3 & $0.68(0.38-1.23)$ & 0.200 \\
\hline 4 & $0.27(0.14-0.55)$ & $<0.001$ \\
\hline 5 & $0.32(0.15-0.69)$ & $<0.001$ \\
\hline $\begin{array}{l}\text { Notice important changes } \\
\text { in different temperatures }\end{array}$ & $2.25(1.44-3.49)$ & $<0.001$ \\
\hline Symptoms worsen with heat & $5.16(3.17-8.42)$ & $<0.001$ \\
\hline Windows can be open & $0.42(0.27-0.65)$ & $<0.001$ \\
\hline Natural light & $0.39(0.25-0.62)$ & $<0.001$ \\
\hline
\end{tabular}

* Adequacy of light, ventilation, temperature and noise were measured using a 5-level Likert scale, with level 1 as the worst level ("completely inadequate") and level 5 as the best level ("completely adequate").

Abbreviations as in Table 3.

Adequacy of light, ventilation, noise and - to a less degree - temperature at the workplace protected the staff against suffering from the RC's Disease (Table 5). In this regard, people working in the area with natural light

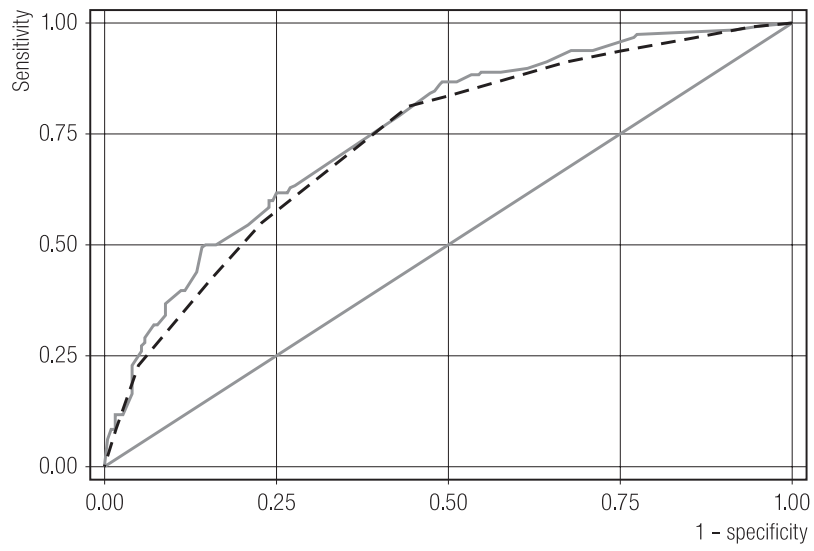

Areas under the ROC curves are 0.7593 and 0.7378 , respectively.

Fig. 1. Receiver Operating Curves (ROC) for logistic regression model (solid line) and for simplified predictive score (dashed line)

$(\mathrm{OR}=0.39,95 \%$ CI: $0.25-0.62)$ or in rooms where windows could be open (OR $=0.42,95 \%$ CI: $0.27-0.65)$ were less likely to report the symptoms of the RC's Disease (Table 5). Although the perceived adequacy of temperature had no dose-effect relationship, people noticing important changes in the workplace temperature $(\mathrm{OR}=2.25$, 95\% CI: 1.44-3.49) and people whose symptoms worsen due to heat $(\mathrm{OR}=5.16,95 \% \mathrm{CI}: 3.17-8.42)$ were at a higher risk for suffering from the RC's Disease.

\section{Predictive model}

A predictive model was constructed via stepwise multiple logistic regression; it included personal antecedents of allergy, hypercholesterolemia, growth pain, intolerance to meals, symptoms worsening with heat at the workplace, and professional category (Table 6). The area under the ROC curve for this model was 0.7593 (Figure 1, solid line). In order to obtain an easy-to-use predictive tool, a score was constructed based on the odds ratios of the predictive model (Table 6, last column). This simplified tool has the area under the ROC curve equal to 0.7378 (Figure 1, dashed line), showing that its predictive power is only a bit lower that the logistic model one. Table 7 displays accuracy measures for the simplified model; the 
Table 6. Predictive model of being a case (obtained by multiple logistic regression)*

\begin{tabular}{lllc}
\hline \multicolumn{1}{c}{ Variable } & OR $(95 \% \mathrm{CI})^{* *}$ & $\mathrm{p}^{* *}$ & Predictive score \\
\hline Personal antecedents of alergy & $1.70(1.05-2.76)$ & 0.030 & +1 \\
Hypercholesterolemia & $2.04(1.20-3.45)$ & 0.010 & +1 \\
Growing pains & $1.96(1.05-3.63)$ & 0.030 & +1 \\
Intolerance to foods & $2.41(1.26-4.62)$ & 0.010 & +1 \\
Symptoms worsen with heat at the workplace & $5.44(3.24-9.12)$ & $<0.001$ & +2 \\
Profession (reference: nurse) & & \\
$\quad$ midwife & $0.49(0.19-1.24)$ & 0.130 & -1 \\
nurse assistant & $0.95(0.58-1.58)$ & 0.860 & 0 \\
porter & $0.32(0.06-1.63)$ & 0.170 & -1 \\
administrative & $3.09(1.04-9.17)$ & 0.040 & +1 \\
$\quad$ other & $1.29(0.39-4.30)$ & 0.680 & 0 \\
\hline
\end{tabular}

* The predictive score (last column) was obtained by simplifying logistic regression results in order to have an easy-to-use tool for predicting cases. ** Odds ratios and $\mathrm{p}$ values adjusted by the remaining variables in the model. Abbreviations as in Table 3.

Table 7. Measures of accuracy for the simplified model developed in Table 6

\begin{tabular}{lcccccc}
\hline \multirow{2}{*}{ Score } & \multicolumn{2}{c}{$\begin{array}{c}\text { SBS } \\
\text { (n) }\end{array}$} & & & & \\
\cline { 2 - 4 } & yes & OR $(95 \% \mathrm{CI})$ & Sensitivity & Specificity & Likelihood ratio \\
\hline$\leq 0$ & 17 & 89 & $1.00($ ref.) & 100.0 & 0.0 & 0.26 \\
1 & 21 & 66 & $1.67(0.81-3.42)$ & 91.4 & 32.3 & 0.43 \\
2 & 53 & 59 & $4.70(2.39-9.27)$ & 81.3 & 56.3 & 1.22 \\
3 & 62 & 48 & $6.76(3.33-13.72)$ & 55.2 & 77.5 & 1.76 \\
4 & 38 & 12 & $16.58(5.93-46.4)$ & 24.7 & 94.9 & 4.30 \\
$\geq 5$ & 12 & 2 & $31.41(4.86-203.0)$ & 5.9 & 99.3 & 8.21 \\
\hline
\end{tabular}

SBS - Sick Building Syndrome. Other abbreviations as in Table 3.

higher the score, the higher the odds ratio, the sensitivity and the likelihood ratio, and the lower the specificity.

\section{DISCUSSION}

Any a priori characterization of a health problem occurring inside a hospital as SBS could enter into conflict with the interests of administrators, professionals, labor unions, employees themselves, or even patients. Cluster analysis allows us to define the case of RC's Disease in a hypothesis-free way, which shields it against prejudiced criticisms. The fact that our case definition is substantially in agreement with the usual SBS definitions [7,8] confirms its reliability.

Previous studies usually reported SBS as an illness defined as a number of a priori lists of symptoms. For instance, Brauer et al. [9] asked for the information on the suffering or not from eight symptoms: eye irritation, nose irritation, nasal congestion, throat irritation, hoarseness of voice, fatigue, headache, and concentration difficulty; then, they 
constructed two indexes: one for the mucous syndrome (ranging 0-5) and another for the general syndrome (ranging 0-3). Nordström et al. [10], on the other hand, produced a 0-26 symptom score. Thus, choosing cut-off points for defining SBS from these indexes is somewhat arbitrary and could both overestimate (if the chosen cut-off point has low specificity) or underestimate (if low sensitivity) the magnitude of the health problem. It is noteworthy that these definitions, as well as the definition of the RC's Disease, are based on a number of unspecific symptoms and are purely operative in spite of whether they have a pathological basis or not. In this study, the perceived indoor environment quality at the workplace is strongly related with being a case of the RC's Disease: light, ventilation and noise classified as adequate exhibit a dose-response protective effect: the more adequate the environment, the lower the odds of the disease. Moreover, some control over the environment (for instance, the possibility of opening windows or having natural light) also has a protective effect. The previous reports identified inadequate light [4,9,11], inadequate temperature [4,9,11-14], dust [4,9], dry air [9], noise $[4,9,11]$ and ventilation as the risk factors of SBS [3]. Temperature was not clearly related with the RC's Disease, although Norbäck and Nordström [1] found a positive relationship: the higher the temperature, the higher the odds of SBS. They also revealed positive associations with the $\mathrm{CO}_{2}$ concentration, which have not been studied here, but not with the relative humidity and the air exchange rate. In their previous study [15], they reported a non-significant decrease in the symptoms after an intervention for increasing the relative humidity; the small sample size of that study, however, prevents any conclusive interpretation. Similar results were found in a Finnish study developed in 1990 [16].

Most occupational variables do not show any relationship with the disease. It is noteworthy that porters, who are less attached to a particular place, and people working on changing shifts, who are less attached to a particular time, are burdened by a lower risk of developing the disease. This important point, which - to our knowledge - has not been previously reported, supports the usual thinking of SBS as related to characteristic environmental exposures.

Several personal antecedents usually associated with immune system disorders have been found to be positively associated with the RC's Disease. They include food intolerance, unexplained episodes of fever, allergies, urticaria or angioedema, skin sensitivity to sunlight, oral ulcerations, inflammation in distal joints or livedo reticularis. These associations can support an immunologic mechanism for SBS [17,18].

A multivariate score for predicting the RC's Disease has been constructed; such a score requires further validation in independent samples before it can be considered applicable in other places. So far, it has had local utility: Residencia Cantabria is expected to remain open only for a couple of years, and during this time its healthcare workers will be relocated into another building; thus, significant engineering investments to improve the indoor environment cannot be anticipated. This score, however, can be used for prioritizing healthcare workers relocation: people scoring higher should be the first to be moved from the Residencia Cantabria.

It is worth noting that this study was cross-sectional, so its results should be carefully interpreted: reporting bias and incidence-prevalence bias could be responsible for some of the associations reported here. More importantly, inverse causality cannot be discarded either: as previously reported, some people would be more prone to inform of inadequate indoor environment after suffering from some symptoms, irrespective of whether they could be related with SBS or not [4].

Summarizing, a disease convincingly associated with the perceived indoor environment quality in a general hospital was characterized. The results reported here support the hypothesis that this disease had an immunologic substrate. A multivariate score was developed for identifying healthcare workers with a higher risk of developing the disease, in order to take administrative measures of prevention. 


\section{ACKNOWLEDGMENTS}

This study was supported by the Hospital Universitario Marqués de Valdecilla.

\section{REFERENCES}

1. Norback D, Nordstrom K. Sick building syndrome in relation to air exchange rate, $\mathrm{CO}(2)$, room temperature and relative air humidity in university computer classrooms: An experimental study. Int Arch Occup Environ Health. 2008;82: 21-30, http://dx.doi.org/10.1007/s00420-008-0301-9.

2. Burge PS. Sick building syndrome. Occup Environ Med. 2004;61: 185-90, http://dx.doi.org/10.1136/oem.2003.008813.

3. Fisk WJ, Mirer AG, Mendell MJ. Quantitative relationship of sick building syndrome symptoms with ventilation rates. Indoor Air. 2009;19:159-65, http://dx.doi.org/10.1111/j.16000668.2008.00575.x.

4. Brauer C, Kolstad H, Orbaek P, Mikkelsen S. The sick building syndrome: A chicken and egg situation? Int Arch Occup Environ Health. 2006;79:465-71, http://dx.doi.org/10.1007/ s00420-005-0075-2.

5. Rios JLD, Boechat JL, Gioda A, dos Santos CY, Neto FRD, Silva JRLE. Symptoms prevalence among office workers of a sealed versus a non-sealed building: Associations to indoor air quality. Environ Int. 2009;35:1136-41, http://dx.doi. org/10.1016/j.envint.2009.07.005.

6. Stata Statistical Software. Release 10. College Station, TX (USA); StataCorp LP 2007.

7. Redlich CA, Sparer J, Cullen MR. Sick-building syndrome. Lancet. 1997;349:1013-6, http://dx.doi.org/10.1016/S0140-6736 (96) 07220-0.

8. Ezratty V. The sick building syndrome (SBS). Presse Med. 2003;32:1572-9.

9. Brauer C, Kolstad H, Orbaek P, Mikkelsen S. No consistent risk factor pattern for symptoms related to the sick building syndrome: A prospective population based study. Int Arch Occup Environ Health. 2006;79:453-64, http://dx.doi. org/10.1007/s00420-005-0074-3.
10. Nordstrom K, Norback D, Akselsson R. Influence of indoor air quality and personal factors on the sick building syndrome (SBS) in Swedish geriatric hospitals. Occup Environ Med. 1995;52:170-6, http://dx.doi.org/10.1136/oem.52.3.170.

11. Ooi PL, Goh KT. Sick building syndrome: An emerging stress-related disorder? Int J Epidemiol. 1997;26: 1243-9, http://dx.doi.org/10.1093/ije/26.6.1243.

12. Burge PS, Robertson AS. Sick building syndrome; environmental comparisons of sick and healthy buildings. Indoor Air. 1990;1:479-83.

13. Jaakkola JJK, Heinonen OP, Seppanen O. Sick building syndrome, sensation of dryness and thermal comfort in relation to room-temperature in an office building - need for individual control of temperature. Environ Int. 1989;15:163-8, http://dx.doi.org/10.1016/0160-4120(89)90022-6.

14. Skov P, Valbjorn O. The "sick" building syndrome in the office environment - The Danish town hall study. Environ Int. 1987;13:339-49, http://dx.doi.org/10.1016/01604120(87)90190-5.

15. Nordstrom K, Norback D, Akselsson R. Effect of air humidification on the sick building syndrome and perceived indoor air quality in hospitals: A four month longitudinal study. Occup Environ Med. 1994;51:683-8, http://dx.doi.org/10.1136/oem.51.10.683.

16. Reinikainen LM, Jaakkola JJ, Seppanen O. The effect of air humidification on symptoms and perception of indoor air quality in office workers: A six-period crossover trial. Arch Environ Health. 1992;47:8-15, http:// dx.doi.org/10.1080/00039896.1992.9935938.

17. Bakke JV, Wieslander G, Norback D, Moen BE. Atopy, symptoms and indoor environmental perceptions, tear film stability, nasal patency and lavage biomarkers in university staff. Int Arch Occup Environ Health. 2008;81:861-72, http://dx.doi.org/10.1007/s00420-007-0280-2.

18. Shusterman D, Murphy MA, Balmes J. Differences in nasal irritant sensitivity by age, gender, and allergic rhinitis status. Int Arch Occup Environ Health. 2003;76:577-83, http://dx.doi.org/10.1007/s00420-003-0459-0.

This work is available in Open Access model and licensed under a Creative Commons Attribution-NonCommercial 3.0 Poland License - http://creativecommons.org/ licenses/by-nc/3.0/pl/deed.en. 